\title{
The Design and Implementation of the Flash Animation Film: CG Gallery
}

\author{
Li Xinyang, Mao Mengsi \\ Jiangxi Tellhow Animation Vocational College, Nanchang, Jiangxi, 330200
}

Keywords: Flash, animation, CG Gallery, design scheme

\begin{abstract}
Flash animation is a form of digital media with simple images, which is popular with exhibition activities, such as commercial advertising, online game planning and teaching simulation. Since the advent of animation for more than one hundred years, the animation making has long been a difficult business activity for the average people. Until the invention of the Flash software for animation design, people begin to change their ideas. The developing Internet has made the animation be composed by just one person, which marks a breakthrough in the animation design history. The software boasts prominent advantages, meanwhile, it has some weaknesses. How to make full use of the software in a scientific and rational way is one of the most important issues in the animation design in China. [1] The paper, taking CG Gallery, an animation film as the research object, analyzes the status quo as well as tendency in the future of animation film both at home and abroad in detail and overviews the history of animation film. As a substantive paper on the production of Flash animation as well as its technology, the paper hopes to provide a help for the workers in Chinese animation sector.
\end{abstract}

As one of the important economic sectors in China, the animation has a long history with teenagers and children as its major audience. The paper, compares the two-dimensional animation technologies domestically and globally, demonstrates the development of animation film. It analyzes the achievements as well as shortcomings of China's animation in recent years taking CG Gallery as a specific example.

\section{The origin and development of animation in China}

\subsection{The manifestation pattern in the early stage (see the figure 1)}

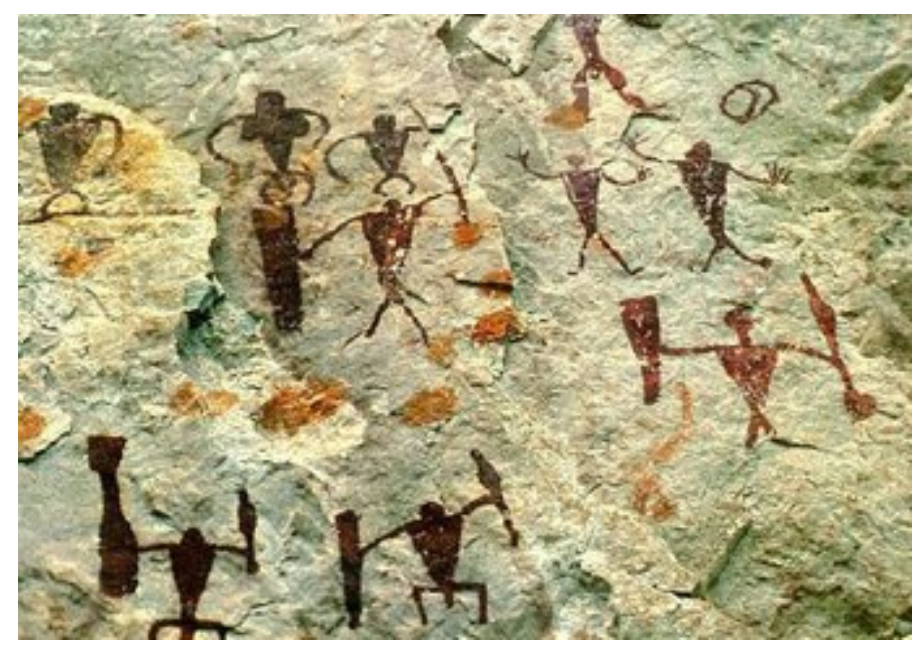

Figure 1

The birth of animation film can be dated back to the Stone Age. And Prudhommeau, a famous French archaeologist had discovered a series of images of primitive man curved by stone in the wall about 20,000 years ago. And the vivid images can be easily recognized even now. thus, it can be seen that, people at that time had shaped the habit of recoding life by images, or say, it was a way of entertainment at the time. And similar fine art can be seen in the fresco, tomb paintings, as well as 
the vase in the ancient Greece, which can be regarded as one of the earliest origins of the animation in the world. [2] In 1832, the so-called Phenakistoscope was invented, realizing the simple animation playing of fine art, which is the earliest machine to display continuous images as the animation in the world. The Phenakistoscope could only play some simple hand-drawn patterns successively at that time, creating a dynamic visual feeling. The principle of the Phenakistoscope is to put some hand-drawn patterns with differences in the action into a disc rotating at a rate. One the disc rotates, the images flowing can be seen from the gap of the rotating disc, which is called animation later.

\subsection{The development and production means of animation}

The animation production requires the design of various auxiliary tools, art skills and mathematics foundation of personnel. And traditional animation techniques give birth to the modern animation production. Although animation production and playing utilize mainly the computer tools and operation technologies, many principles are the same as the thaumatrope in the West and the film animation. [1]

Thaumatrope was early applied in the commercial animation. Due to the low cost, simple manufacturing and easy carrying, the thaumatrope was chased after by some animation production companies. And in the late $19^{\text {th }}$ century, such tools could be found in some Chinese towns. Generally, it was placed in the streets for free viewing for one person at a time. While in 1982, Joseph Prado invented the first film showing device which could produce a complete animation. And Stuart, an American cartoonist produced the first complete animation in 1906, named Humorous Phases of Funny Faces. He lined more than 3000 bills one by one in the film and released in the public, causing a sensation at the time.

The progress in mechanical tools has driven the development of animation in a huge degree. High and bright projector can project the images in the film into the large screen in the distance, demonstrating the charm of animation for audience. Later, animation is sold in the form of tickets, and audience must pay to watch the animation. In this way, challenges are posed in front of animator, who must make brilliant films to attract more audience for huge profits.

After entering into the $21^{\text {st }}$ century, major countries have applied the computer technology to make animation, in particular the United States, Japan and South Korea, whose animation technology is mature. And advanced cosmic industry in Japan has promoted animations flow in the market. And Japanese buy over eight cosmic books and magazines per person each year, most of animation images are made by computers. In the United States, the Hollywood also boasts animation making technology, and Disney is the world's largest animation production company, who continues efforts to make animation in the traditional way for years. However, with the popularization of computer technology, the Disney begins to introduce computer technology comprehensively to make animation, and produces a set of animations made by computer technology, for example, the Lion King, (see figure 2) enjoying a high reputation in the world is made by computer technologies.

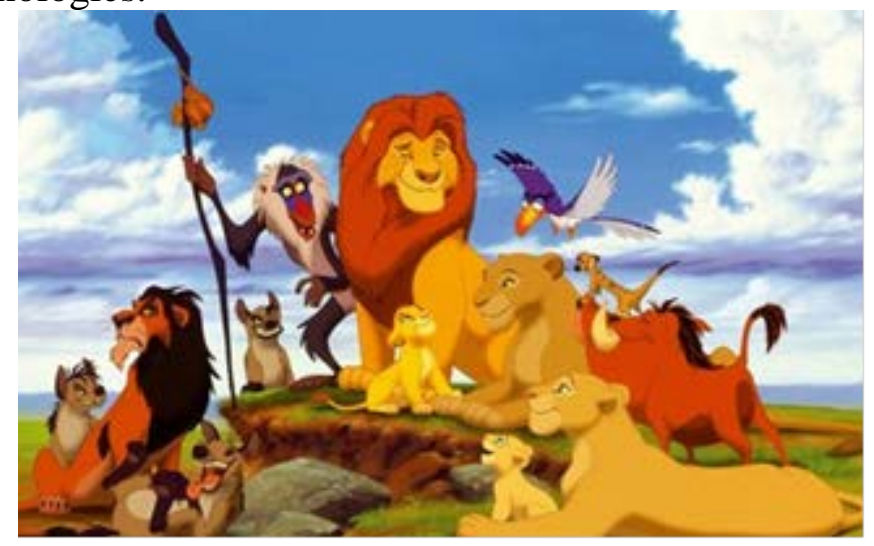

Figure 2 


\section{Demand analysis of CG Gallery}

\subsection{The key and difficulty in the design}

Since CG Gallery is a Flash animation, the image design can be classified to the artistic designing, which proposes high requirements for the designers. The major drafts are composed by CG Website, which requires high capacity for art of producers.

The production of CG Gallery needs coordination among various animation software, team spirit of production teams, as well as advanced technological means to makes flexible and integrated animations. In most cases, the production rate of images manifests the technology of a production team, and the animation production depends on the splicing of a large number of pictures. The quality of each picture should be ensured in the production, and the joining of pictures should be perfect to achieve the ideal effect. As for the key and difficulty in the design, firstly, quality animation figures as well as scenes should be devised at a fast rate, different scenes of all figures should be changed timely to meet the needs of the plot. It can be concluded that the animation making is not an easy work. First of all, the production ability of animation design software is limited, which demands designers to make full use of imagination. The key to animation images is the complexity control of the graphics. Production software like Illustrator should be utilized to help the production. Only by fully utilizing all available resources, can the technological difficulties be solved efficiently. [5]

\subsection{Acquisition mode of needs}

The CG Gallery utilizes several animation software. The major needs of the images mainly come from the functions of the software itself as well as the imagination of the designers. It can be seen that, the digital animation making is superior to the traditional method in light of image making by the analysis of the software function. And two-dimensional animation has some defects in the design and production means: the major function of software is to arrange animation images of the frame and timeline purposefully. In addition, the drawing instrument is more simple than the professional instrument, the integration of various technological means can show better images. And it is found that, the animation design by the Flash has some weaknesses, such as the simple expression technique, which fails to meet the needs of current animation industry. Thus, it is important to use other animation software to achieve the ideal effect. Nonetheless, the effect is still not ideal, causing simple expression lack of sense of image and decoration. And the authors learned that, Flash animation design are separated from graphic design in most universities as well as the animation studios. Though experts have stressed that, the animation design and graphic design supplement each other, which is ignored by people in a long period. Therefore, the professionals have narrow knowledge for the technology. From this point of view, it is inevitable to combine the graphic and the animation design. [6]

\subsection{The demand description}

Firstly, according to the available data storage, the Flash images are mainly represented by vectorgraphs. Given this characteristics, the plot of animation can be judged to be displayed by graphs. In order to improve the production efficiency, the animation images should be as simple as possible, and lines should be less to demonstrate rich content, which demands strong artistic foundation as well as bold imagination of designers. In a word, the main work of Flash animation making consists of graphing and material gathering.

\section{The design of CG Gallery}

\subsection{Function in business}

The business function of the draft design of CG Gallery is especially important. In most cases, the major function of the business is to transform drafts into editable computer graphics. In the real transformation, the draft image as well as gestures cannot be changed, whose function mainly relies on three technological means: graphic transformation, artificial tracing, as well as sample collection. 
The graphic transformation is just to modify graphics lightly, rather than transforming the original graphics greatly. So the function is to embellish the graphics. What is more, the working principles of images and graphs are different in image design and storage although they are both animation material designs.

\subsection{Function in material}

The material processing is to modify the lines, outline, colour and shade. [7]

The function of line modification: the major function of computer software is to modify the lines by the nodes in the Bezier, which can determine the specific positon of nodes in a line. Meanwhile, through simple operation, the curve degree can be controlled, which is the foundation of animation material design. For artificial modeling, the Bezier is more convenient, and for plant images, the Bezier can control the related details in the production, which requires less curves to precisely portray the key points. Usually, the embellishment of images by the mouse is a good way, however, due to its complex work, and inconvenient handle operation, the embellishment by Flash will easily encounter problems, hindering the post production of animation images. Hence, the designers can utilize the function of elastic bending, the operand is still the Bezier, while the operation is rather easy: parts of nodes in the curve can be considered as a whole. In this way, some links can be omitted in the modification, achieving relatively ideal embellishment.

Brush stroke: the brush stroke in the Flash is relatively weak, and some problems will emerge in the real operation, the contour can change the thickness of the whole instead of the line shape. According to the plot, the line shape can be changed with the help of other animation software, which can be said to be a defect of the software.

\section{The realization and test of CG Gallery}

\subsection{Animation modeling}

The static images in the animation are mainly showed by roles, prop and background images. The drafts will be processed by manual tracing, then, the static scenes will be embellished by adding or modifying the lines. The production process of static images refers to the setting and adjustment of the time and position of the processed images to guide the production of animation. In this process, the material will not be processed,

\subsection{The production of in the business layer}

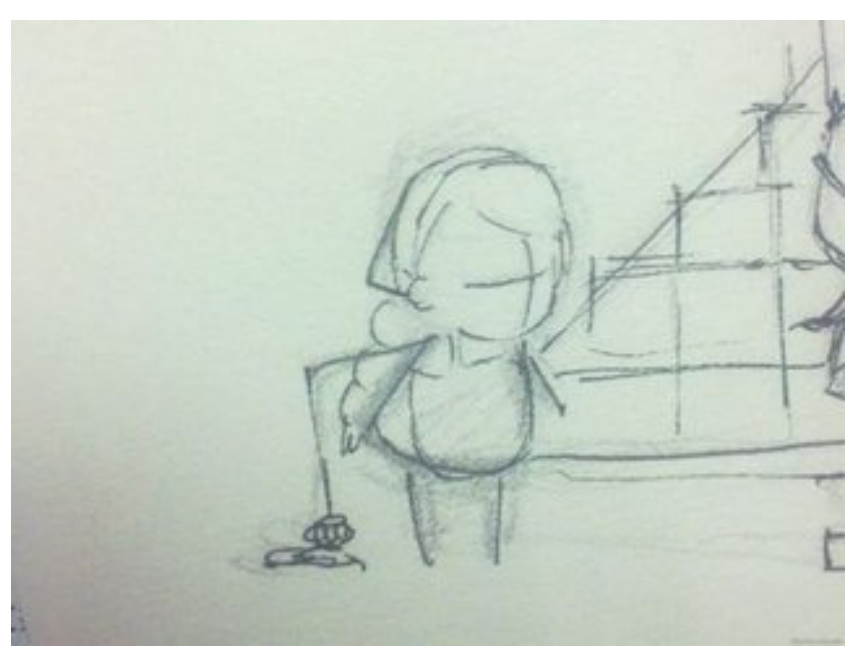

Figure 3

The drafts offered by CG website are mainly hand drawings with many uncertainties as well as rough lines. (see figure 3). If these lines are directly used to transform graphs, it will be hard to achieve ideal effect. Therefore, before the graphics transformation, the drafts shall be processed. Generally, they are processed by Photoshop, making rough lines smooth, meeting the needs of 
animation design.

\section{Conclusion}

Throughout the production of CG Gallery, it can be seen that the animation proposes high requirements for designers as well as the software with a long time. The paper, clarifies and discusses the design and implementation of CG Gallery in hope of advancing the development of animation industry in China.

\section{Acknowledgements}

Fund Item: The paper is supported by the science and technology project of Ministry of Education of Jiangxi Province, named Applied Research on the Development of Ganyouji-A Tourist APP with the Characteristics of Jiangxi Province (Item Number: GJJ171414)

\section{References}

[1] Luo Nan. Design and implementation of "CG gallery" of Flash animation propaganda film [D]. Shandong university, 2013.

[2] Jiao Xiang. On the performance of visual and audio-visual beauty of Flash website [J]. Journal of changsha civil affairs vocational and technical college, 2014, 23(04):61-64.

[3] Feng Wenjun. Design ideas and technology realization of the NOC award-winning animation "bubble of innovation" -- and the application of Flash animation in popular science education [J]. Art and design (theory), 2016, 2(04):115-117.

[4] Peng Bo. On the synthesis function of FLASH powerful 2d animation [J]. Audio-visual, 2015,12 (12):71-72.

[5] Deng Tian. On the application of FLASH animation in middle school chemistry courseware [J]. Computer knowledge and technology (academic communication), 2017, 26(13):208-209+239.

[6] Huang Li. On the features and advantages of Flash animation [J]. Brand (theoretical monthly), 2015, 23(12):132+143.

[7] Cen Mengyi, Zheng Jiachin, Liao Xiaofang. On the lens design of Flash animation [J]. Computer knowledge and technology, 2014, 10(01):141-142. 